\title{
Scientific (E)quality
}

\author{
Curt Rice, University of Tromsø
}

Interdisciplinary Science Reviews

Special Issue on Gender in Science

To be published in June 2011.

On June 12th, 2002, the government of Norway announced the names of 13 groups that had been selected to create Norway's first Centers of Excellence. These groups would receive privileges most researchers could only dream of. Well-equipped with all they could need, they would take Norwegian research to new heights in Europe and beyond.

The Center of Excellence program was portrayed as the flagship program of the Research Council of Norway. In the inevitable public debate following the press conference that morning, the selection process itself was characterized as the most rigorous ever implemented by the Research Council.

During the announcement, the 13 of us who would lead these centers were called forward. We stood there proud and hopeful, feeling like crown princes in the fiefdom ruled by our Minister of Education and Research. And we certainly looked the part, standing there together in our dark suits and ties -- all 13 of us. One could be forgiven for finding it difficult to distinguish among the members of the group; every one of the new Center Directors, after all, was a man.

\section{Role Models for Young Scientists}

The press conference that spring day was not just about the Centers of Excellence. There was one more competition winner to be announced.

Elementary school classes all over the country had spent months carrying out demanding scientific investigations, vying for the title of Nysgjerrig Per [Curious Per]. The award that year would be presented by a real Crown Prince, HRH Håkon Magnus of Norway. Scores of giddy schoolchildren were present and several of the classes demonstrated their projects. The youngsters were brimming with excitement and enthusiasm for science. There were many, many boys present. And there were many, many girls, too.

It was no accident that these two awards were made at the same press conference. The organizers' clever idea was that the young schoolchildren would look at the Directors of the new Centers of Excellence and see their own futures. We would inspire them, motivate them, help them to realize what they could become.

The Directors of the new Centers of Excellence and the winners of the Nysgjerrig Per competition were in that auditorium together, at the same time. But it felt like a time 
warp. We were supposed to be a picture from the pupils' future; but the 13 of us collectively looked much more like a stiff painting from their past.

And it wasn't just the girls that morning who couldn't see their futures in the group of Directors. It was the boys, too. True, the boys could at least see individual role models of the same sex, which the girls could not. But the striking thing about the winners of the Center of Excellence competition became clear only when looking at them as a group. Even for the schoolboys who were present, that group couldn't reveal a snapshot of the future. When those boys are adult scientists, after all, they won't be working exclusively with men. There won't be groups that look like the one that was standing in front of them that morning. And while it was easy to see how our selection had in some sense failed the girls in attendance, it turned out that we had just as compellingly failed the boys.

Of course, another perspective on this event could be that we didn't fail anyone. Instead of suggesting that the young prize winners and their friends might see their future in the group of men in front of them, perhaps it was we suited ones who were seeing the future in the enthusiastic schoolchildren -- a future that includes gender equality at all levels of science. With the school groups being divided approximately evenly between boys and girls, perhaps an equal distribution of the sexes among a future cohort of Directors of Centers of Excellence is inevitable; perhaps it's just a matter of time.

\section{Time heals all wounds}

Is it reasonable to hope that time is all that's needed to correct the skewed distribution of the sexes among university professors? In Norway, for example, $60 \%$ of all postsecondary students are women. ${ }^{1}$ Among $\mathrm{PhD}$ candidates, $52 \%$ are women. That falls to $45 \%$ when we look at our post docs and to $35 \%$ for Associate Professors. By the time we get to the top of the heap, we see that of all Full Professors in Norwegian universities and colleges, only $20 \%$ are women. ${ }^{2}$

All of these numbers for women are higher than they were 10 years ago. So can't we just wait? Isn't it really the case that gender balance among Full Professors will be achieved not so long after gender balance among Associate Professors is achieved? And won't gender balance among Associate Professors be achieved soon after we achieve gender balance among those headed for academic careers? Isn't it all really just predestined?

In the following pages, I will argue that time alone cannot guarantee a change in the situation. But I will also identify important reasons why the situation is worth changing. These reasons -- each from its own perspective -- feed the broader claim that gender balance improves scientific quality. Our research is better when gender balance is better.

\footnotetext{
${ }^{1}$ http://www.ssb.no/emner/04/02/40/utuvh/tab-2011-01-27-01.html from Statistics Norway.

${ }^{2}$ Statistics on Women in Research. http://www.nifustep.no/Norway/Sider/STATISTIKK/FoUstatistikk/Kvinner\%20i\%20forskning/Kvinneriforskning.aspx Nordic Institute for Studies in Innovation, Reseach and Education.
} 


\section{Attrition}

There are at least two reasons to question the inevitability of time as a solution to getting more women into the highest levels of academia. One of these involves potential structural impediments: If there are structural barriers keeping women from joining the highest ranks, then there is no reason to think that waiting alone will solve the problem. In the present discussion, I leave further consideration of this matter aside, and focus instead on the problem of attrition.

Women leave academia in greater numbers than men. This is not simply because women who don't get jobs in academia have no choice but to leave; the attrition is in part because women choose alternative career paths. Because the rate of voluntary attrition can change, it is logically possible to increase the numbers of women at lower levels without lifting the numbers at higher levels.

When we acknowledge that rates of attrition can vary, and when we acknowledge that women may leave academia for various kinds of reasons, then it becomes simply a logical error to claim that a proliferation of women at lower levels will inevitably escalate the number of women at higher levels. ${ }^{3}$ It might just facilitate the exodus. Witnessing the departure of peers and mentors could easily create a snowball of attrition; more women at lower levels who don't make it to the top could yield more women at lower levels who don't even try.

This is just logic. Those who claim that time will inexorably increase the percentage of women professors are building an argument on the assumptions that there are no structural barriers and that the rate of attrition for women is stable or declining. But an equally valid alternative is that increased attrition will eliminate any effect of increased numbers at lower levels.

To make the discussion more concrete, recall the Norwegian facts. Currently, 52\% of $\mathrm{PhD}$ students are women while only $35 \%$ of associate professors are. If gender equality among associate professors means that $50 \%$ should be women, and if our tool for reaching gender equality is patience, it's going to require a lot of patience indeed.

If we imagine a cohort of $100 \mathrm{PhD}$ candidates who will ultimately become a cohort of 20 associate professors, we can make the Norwegian numbers clearer. 52 of the $\mathrm{PhD}$ candidates are women, but only 7 of the associate professors come from that part of the pool. 48 of the $\mathrm{PhD}$ candidates are men, and they will occupy 13 of the associate professor positions. This means that along the way from the $\mathrm{PhD}$ to the associate professorship, $87 \%$ of the women have left compared to $73 \%$ of the men. To put it more strikingly, the small half of the pool, namely 48 men, get about twice as many of the associate professor positions as the big half does, i.e. the 52 women. As we will see below, the situation in specific fields can in fact be much worse.

Is attrition in part voluntary? Could we change it? And if we could, how much time would it take to achieve parity? I turn now to these questions.

\footnotetext{
${ }^{3}$ For related evidence and discussion see Neugebauer KM (2006) Keeping Tabs on the Women: Life Scientists in Europe. PLoS Biol 4(4): e97. doi:10.1371/journal.pbio.0040097
} 


\section{Why women leave}

In a report on the career plans of $\mathrm{PhD}$ students in chemistry in the $\mathrm{UK}$, attrition is a central theme. ${ }^{4}$ The facts established in this study document a decline in the intention of $\mathrm{PhD}$ students to pursue research careers. At the beginning of their $\mathrm{PhD}$ work, $72 \%$ of the women intend to pursue research careers while only $61 \%$ of the men have the same intention. As they approach the end of their $\mathrm{PhD}$ period, the number of men still intending to pursue a research career has dropped to $59 \%$. For the women, however, the number has plummeted to $37 \%$. This means that $97 \%$ of the men who at the beginning of their $\mathrm{PhD}$ intend to pursue a research career maintain that plan at the end of their studies. For women, the number is $51 \%$.

Why does this happen? What do the women say when asked about their changing plans? Fortunately, the report offers several observations, almost all of which concern the workplace. For example, a larger portion of women than men felt isolated and excluded in their research group. They were uncomfortable with the culture of the group, including issues such as working patterns, time expectations and the level of competition between members. Women in greater numbers than men also reported the view that the frustration and stress of the PhD process would only be prolonged by a career in research.

Many women explain their choice to leave by invoking issues about the workplace and in part about personal-professional balance. For example, women view academic careers as overwhelming and solitary. Some have actually been advised that being a woman will work against them in academia. They find short-term contracts to be incompatible with family life, and they conclude that success in academia entails sacrifices as a mother.

Differences in the rate of attrition between men and women can be seen later in careers also. A study carried out in Norway revealed that even among academics with permanent positions, women leave in greater numbers than men. ${ }^{5}$ Among the group of women academics at Norwegian universities in 1991, only $50 \%$ of them were still in the system six years later, while $61 \%$ of the men were. ${ }^{6}$ After 10 years, the numbers have dropped to $42 \%$ and $51 \%$ respectively. While mobility between universities and other sectors may have many positive benefits, it is clear from these data that women identify benefits from leaving academia more than men do.

This study also reports a number of differences in perceptions of the workplace

\footnotetext{
${ }^{4}$ The chemistry PhD: the impact on women's retention. A report prepared by Jessica Lober Newsome for the UK Resource Centre for Women in SET and the Royal Society of Chemistry. 2008. http://www.rsc.org/images/womensretention tcm18-139215.pdf

${ }^{5}$ Kvinner og menn -- like muligheter? Om kvinners og menns karriereveier i akademia. [Women and men -- equal opportunities? On women's and men's career paths in academia.] Elisabeth Hovdhaugen, Svein Kyvik and Terje Bruen Olsen. Nifu-step report 25/2004. http://www.nifustep.no/Norway/Publications/2004/S-2004-25.pdf

${ }^{6}$ These numbers include both early career researchers who may not have permanent positions and senior positions, and the separation of the numbers is not possible. But based on earlier tables regarding attrition of early career researchers, it is clear that also women in permanent positions leave in greater numbers than men.
} 
among academics with permanent positions. Here, too, women report less satisfaction with the nature of collaboration and interaction. ${ }^{7}$ They report in greater numbers than men dissatisfaction with the creativity and innovation of the research group and they report a greater wish for more collective planning.

From research of the type discussed here, it becomes clear that attrition rates reflect more than failed attempts to obtain positions in academia. If that were the only barrier, it would be easier to imagine gender parity being achieved as more women appear in the applicant pools. But the assumption that more female $\mathrm{PhD}$ students will yield more female applicants at the next step of the academic career is unwarranted. Women leave academia because of the nature of the workplace. Until this is addressed, there is no reasonable expectation that the situation will change. Until we make our workplace better, science will continue to pay the high price of a hidden brain drain. ${ }^{8}$

\section{Studies on the effects of time}

Even if it is logically fallacious to assert that the combination of more women at lower levels and time will necessarily lead to more women at higher levels, we could nonetheless ask if this combination is likely to have an effect. Is it reasonable to hope that increased numbers of women taking PhDs will lead to increased numbers of female professors at some point down the road? And, if it is at least likely that there will be some effect, how long will it take? If time is our primary tool, when will parity to be achieved?

To gain some insight into this issue, we can briefly consider recent results in Norway and The Netherlands. In a report on gender equality scenarios in the higher education sector published in 2006, the situation in Norway is described as follows. ${ }^{9}$ If progress continues at the rate seen in the 1990s and 2000s, it will take 25-30 years to achieve gender parity in the aggregate of scientific positions at universities and colleges. For professorships, it will take much longer. And these figures are built on the assumption that new hires at the rank of associate professor will be $50 \%$ women, itself a dubious assumption.

We can see from such studies that the need for creative action is urgent. To achieve gender parity in academic positions in Norway 2016 would require that $80 \%$ of all hirings be women, an entirely implausible scenario.

The situation in The Netherlands has received careful study recently and the goals are even more distant there. ${ }^{10}$ The Monitor reports that $11.7 \%$ of professors in The Netherlands are women, as of 2008, and that the number is increasing by $0.5 \%$ per

\footnotetext{
7 See also Bear, Julia B. and Anita Williams Woolley. This issue. The role of gender in team collaboration and performance.

${ }^{8}$ For discussion of this concept, see the resources advanced by The Hidden Brain Drain Task Force at http://www.worklifepolicy.org/index.php/section/initiatives

${ }^{9}$ Likestillingsscenarier for UoH-sektoren. [Gender equality scenaria for the higher education sector.] Vera Schwach and Terje Bruen Olsen. Nifu-step working paper 44/2006. http://www.nifustep.no/Norway/Publications/2006/NIFU\%20STEP\%20Arbeidsnotat\%2044-2006.pdf

${ }_{10}$ Emancipatiebeleid voor universiteiten. Een overzicht van in Nederland toegepaste maatregelen. Tineke M. Willemsen and Tanya M. Timmers. 2009. http://www.lnvh.nl/files/downloads/123.pdf
} 
year. ${ }^{11}$ The EU's Lisbon Agreement had a goal of $25 \%$ women professors throughout Europe by 2010. At the current rate of increase, The Netherlands will not reach this level nationally until 2030. The government of The Netherlands revised its goal downward in 2005 , aspiring to reach a meager $15 \%$ by 2010 . This goal also went unmet and at current rates of increase, it will take until 2014 to reach $15 \%$.

\section{Intermezzo}

Shall we try to rectify the gender imbalance at the highest levels of academia? Under discussion above is the familiar call-to-inaction claiming that no measures are necessary. Just look at the standard scissors graph and it will be clear that the dominance of women at lower levels will lead to a dominance of women at higher levels. We could call this the time heals all wounds argument, or THAW.

I have discussed two aspects of the THAW argument. The first of these is its claim of inevitability: The situation may seem frozen, but that has to change. I have argued that this claim crucially fails to account for potential variation in rates of attrition. Women leave academia in higher numbers than men, and we have seen that this is true not only early in careers but later as well. Departure may beget departure, yielding what I called a snowball of attrition.

The logical non-necessity of THAW notwithstanding, there has been progress. But when we study the numbers, we see that it is a slow thaw, at best. The fulcrum of the scissors on the graphs is moving to the right but the movement is so slow -- the conditions are so cold -- that we either will never achieve our goals, or we will achieve them much later than we want.

Change is not inevitable, but it may happen, albeit very slowly. Given this, is there any reason to abandon THAw? Can we do anything to hasten gender equality? Should we? Why?

It is clear that reaching our goals requires doing more than waiting, but if we're going to try to accelerate the thaw, we have to know why. There are many familiar arguments for the importance of gender equality -- matters of social justice, of effective use of resources -- but there are different kinds of arguments, too. In the remainder of this article, I claim that we should try to hasten the thaw for at least three reasons -- reasons independent of matters of social justice that thereby augment them.

\section{Arguments}

If THAW represents the default approach, the strategy for which no argument must be made, if it represents inertia itself, then any attempt to move more quickly along the path to gender equality and balance requires compelling argumentation. Traditional arguments seek such compulsion through collectively oriented argumentation. If $40 \%$ of associate professors are women then the default expectation is that $40 \%$ of the full

\footnotetext{
${ }^{11}$ Women Professors. The state of affairs with respect to women in university positions and academic decision making bodies. Monitor 2009. http://www.lnvh.nl/files/downloads/125.pdf
} 
professors will be women. If in fact only $20 \%$ of full professors are women, then the playing field must not be level, and an argument for gender equality work emerges, namely that fairness requires a level playing field.

When this argument is cast in the terms of social economics, we argue that the playing field must be leveled not out of fairness per se, but because it is wasteful to fail to exploit the resources available, included those represented by the portion of the workforce that is female.

Another example of a traditional argument for the deliberate pursuit of gender equality is that failure to do so inevitably leaves an unfair situation, since men and women approach the workplace differently and any failure to acknowledge those differences will incorrectly evaluate the entire workforce by criteria that are matched to only half of it.

These arguments can compel but not through an egoist philosophy. The egoist will embrace the need to work for gender equality only if such work feeds independently established individual goals e.g. related to scientific production. In the context of academia, if one could argue that an investment in gender equality is an investment in better conditions for research, then faculty who are interested in that can be brought onboard. If one could argue that research groups reflecting gender equality in their composition are more innovative, those who are interested in delivering the best possible scientific results can be engaged in the work of gender equality. If it can be claimed that science that reflects gender issues is better science, then even those who think only about scientific quality will be compelled to think about gender equality.

The traditional arguments are important and compelling. But they are not the only arguments we can construct. They can be supplemented with arguments more directly addressing the core activities of leading scientists. To the extent that these new arguments are correct, the importance of leaving the slow THAW is established, and we can move more quickly towards developing new interventions.

\section{Gender equality and the competitive edge}

We can't just wait, not only because the logic of waiting is flawed since improvement is in fact not inevitable. We also must act now because the results are too important to simply wait for. Action is required because the results of successful action will be better science. I will mention here three perspectives from which it becomes clear that gender equality in the research sector gives better results for the institutions and the research they produce.

My approach shares a perspective with the authors of McKinsey's report Women Matter 2. ${ }^{12}$ "Gender diversity is not just a social concern. Our new study suggests that it could also create a competitive edge to address the global challenges that corporations will face in the near future."

\footnotetext{
${ }^{12}$ Women Matter 2: Female leadership, a competitive edge for the future. McKinsey \& Company. 2008. http://www.mckinsey.com/locations/paris/home/womenmatter/pdfs/women_matter_oct2008_english.p df
} 
Does this quote convey a perspective that is also relevant to science and its practice? Are there arguments for improved gender equality in research-oriented institutions that go beyond "social concern"? Are there reasons to believe that greater gender equality can give better science? Why? How?

There are arguments that improved gender equality can give better scientific results. I sketch three of them here.

\section{Creativity in research teams}

The English chemist William Henry (1775--1836) posed the following question about research: "What is research, but a blind date with knowledge?" Henry's question emphasizes both the heart of research, namely the quest for new knowledge, and its uncertainty. Scientists engaged in basic research do not and cannot know the results of their investigations in advance. They are pushing ahead in the dark. They are on a blind date.

A successful blind date requires creativity and researchers who are on one have to find methods that give answers, that can yield something meaningful. Since modern science is primarily carried out in groups, success depends not just on creative individuals, but also on creative groups.

Is there a connection between gender balance in a group and its creativity? Research suggests that there is. In a recent report, the London Business School concludes that innovation is fed when we "actively construct teams with equal proportions of men and women." ${ }^{13}$ One of the key concepts of innovation, for example, is the ability to construct experimental approaches to solving problems. The teams studied in the LBS report peaked in their experimental capacity exactly at the point of parity in gender distribution in the team. This is typical of the research results on the effects of gender parity in group innovativeness.

Groups can be described as having an intelligence of their own. ${ }^{14}$ And group intelligence is positively influenced by the presence of women in the group. In their discussion of this work, Science Daily writes that "teams containing more women demonstrated greater social sensitivity and in turn greater collective intelligence compared to teams containing fewer women." 15

Gender balance yields creativity. If there is any activity that requires creativity, surely it is basic research. In light of that, we cannot afford to wait for gender equity to just happen; we must find measures that can make it happen much, much sooner than is

\footnotetext{
13 Innovative Potential: Men and Women in Teams. London Business School. 2007. http://www.london.edu/assets/documents/facultyandresearch/Innovative_Potential_NOV_2007.pdf

${ }^{14}$ Anita Williams Woolley, Christopher F. Chabris, Alexander Pentland, Nada Hashmi, and Thomas W. Malone. Evidence for a Collective Intelligence Factor in the Performance of Human Groups. Science, September 30, 2010.

${ }^{15}$ Massachusetts Institute of Technology. "Collective intelligence: Number of women in group linked to effectiveness in solving difficult problems." ScienceDaily 2 October 2010.
} 
possible with a slow thaw. ${ }^{16}$

\section{Gendered research questions}

Yet another perspective on gender equality focuses not on the structure of the research team, but rather on the structure of the research question. Incorporating issues related to gender and sex into research questions, increases the potential for high quality results. The best-known examples of this type are from medical research, which provides less robust evidence for the treatment of women. ${ }^{17}$ Greenspan et al. have discovered in a recent study of publication patterns in the journal Pain, that $79 \%$ of recent animal studies include only males, creating a potentially inappropriate basis for treatment of women. ${ }^{18}$ Other examples from research on heart disease and osteoporosis -- where research done on women is the basis for the treatment of men -are well-established in the literature.

The situation with testing of new drugs tells a particularly clear story about the impact of ignoring sex on the quality of the science. In the U.S., 8 of 10 drugs withdrawn from the market in the period 1997--2001 turned out to pose greater health risks for women than for men. These problems were not evident in the research leading up to marketing because of inadequate attention in the pre-market testing to potential differences between the reactions of men and women to the drugs. ${ }^{19}$

\section{The success of organizations}

While the core of research activity is carried out by groups of scientists working together to formulate and pursue creatively formulated questions and hypotheses through innovatively developed methodologies, there is a larger context for research activity, and an argument for hastening gender equality work is also available in this domain. Research is carried out in organizations and the circumstances for research will be better when the organization is run better.

On this matter, there is extensive evidence that gender equality in leadership has a significant positive impact on organizations. McKinsey's Women Matter 3 identifies an Organizational Performance Profile with nine elements, such as direction, accountability, innovation, capabilities, motivation, work environment and more. ${ }^{20}$ When comparing companies with no women in top management to companies with at

\footnotetext{
${ }^{16}$ A good source for additional references on the relationship between group performace and gender equality is the book How Women Mean Business: A step by step guide to profiting from gender balanced business. Avivah Wittenberg-Cox. 2010. John Wiley \& Sons Ltd.

${ }^{17}$ Women in Science and Medicine. S. Buitendijk, D. Corda, A. Flodström, A. Holdcraft, J. Hunter, E. Pollitzer, T. Rees, C. Rice, L. Schiebinger, M. Schraudner, K. Sjørup, R. Tarrach. vol. 377. March 5, 2011.

${ }^{18}$ Greenspan JD, Craft RM, LeResche L, et al. Studying sex and gender differences in pain and analgesia: a consensus report. Pain 2007; 132: S26-45.

${ }^{19}$ Sex, Drugs, and Risk's Role. Cullen T. Vogelson. Modern Drug Discovery. October, 2001. Volume 4, Nr. 10.

${ }^{20}$ Women Matter 3: Women leaders, a competitive edge in and after the crisis. 2009. http://www.mckinsey.com/locations/paris/home/womenmatter/pdfs/Women_matter_dec2009_english. $\mathrm{pdf}$
} 
least three women in top management, the companies with women are rated by their employees as more effective on every one of these nine elements. Organizations with women in leadership have better economic performance than those run just by men. ${ }^{21}$ Organizations with women in leadership display a greater variety of types of leadership behavior. ${ }^{22}$

These conclusions are relevant for universities in at least two ways. First of all, we can suggest that universities with women in their top leadership will function better in the same ways as we see in other sectors, and thereby create better conditions for the activity of the organization, namely research. This itself should be sufficient motivation to take measures to assure that women are present in leadership teams.

Secondly, the conclusions underscore the importance of work to improve gender equality among larger groups of employees, such as professors and senior researchers. Top leadership at universities is usually drawn from the pool of full professors, such that improved gender balance in the class of professors creates a prerequisite for improvements in the teams running the organization. And, indeed, universities are made up of many organizations including faculties, colleges, departments and centers. The arguments about the importance of including both men and women in the leadership of organizations will apply at all of these levels.

\section{Conclusions}

Gender balance in universities has been achieved at lower levels. Over half of our students are women. In much of Europe, over half of $\mathrm{PhD}$ candidates are women. Near parity has also been achieved in Norway at the level of post docs and associate professors. While there is considerable variation internationally, we share a situation in which the percentage of women at the highest academic ranks is considerably lower than at earlier career stages. Fewer women than men get to the top.

In the face of this situation, there are two important questions. One is whether or not this is a problem, and the other is whether or not it will fix itself with forbearance alone.

Regarding the potential effects of time in achieving gender balance at the highest ranks, I have argued two points. First, I have suggested that there is no logical necessity to the claim that gender equality will inevitably be achieved with the passage of time, given variability in rates of attrition. Secondly, I have noted that the rate of change is such that a reliance simply on time will require considerable patience. Few people working today will still be active in their careers when gender balance is achieved among full professors if the only tool we use is time.

\footnotetext{
${ }^{21}$ This is also demonstrated in The Bottom Line: Corporate Performance and Women's Representation on Boards. Lois Joy, Nancy M. Carter, Harvey M. Wagner, Sriram Narayanan. 2007. Catalyst. http://www.catalyst.org/publication/200/the-bottom-line-corporate-performance-and-womensrepresentation-on-boards

${ }^{22}$ In addition to the McKinsey report, see also Eagly, Alice H. and Johnson, Blair T., "Gender and Leadership Style: A Meta-Analysis" (1990). CHIP Documents. Paper 11. http://digitalcommons.uconn.edu/chip_docs/11
} 
Given this, we have to ask whether there really are good reasons to try to do something more. In addition to well-established arguments about fairness, the importance of role models, and accommodation for different approaches to work, there are new and compelling arguments suggesting that considerable benefits are available to science through a strengthened commitment to gender equality.

Gender balanced groups are more innovative than those that are not. Failure to consider matters of sex and gender in research leads to worse scientific results, less reliable answers to important questions, and potentially to expensive modifications of clinical studies. Furthermore, organizations with better gender equality perform better on many factors, which creates better working circumstances, better performance, and a better context for the pursuit of science.

As we use this knowledge to improve universities, we modify the situation for those curious schoolchildren who watched a stuffy group of men become Directors of Centers of Excellence. We create the circumstances in which they will surpass our work. If we do more than just wait, we have every reason to believe that our efforts to improve gender equality will facilitate their efforts to improve scientific quality. 